\title{
Erratum to: Is self-weighing an effective tool for weight loss: a systematic literature review and meta-analysis
}

\author{
Claire D. Madigan ${ }^{1,4^{*}}$, Amanda J. Daley ${ }^{1}$, Amanda L. Lewis ${ }^{2}$, Paul Aveyard ${ }^{3}$ and Kate Jolly ${ }^{1}$
}

\section{Erratum}

Since publication of the original article [1], a reader observed an error in one of the studies that had been included. The study by VanWormer et al [2] presented the results as pounds and was mistakenly analysed in $\mathrm{kg}$. The results have been re-analysed.

Comparing multi-component interventions including self-weighing with no intervention or minimal control is changed by $0.1 \mathrm{~kg}$ ( $3.3 \mathrm{~kg}, 95 \% \mathrm{CI}-4.1$ to -2.8$)$. The $95 \%$ prediction intervals changed slightly $(-6.7$ to $0.05 \mathrm{~kg}$ versus previously -6.9 to 0.1 ). Figure 2 of the original article should have presented these results, as appears correctly within this erratum.

In addition, the mean difference between intervention and control groups for those with accountability changed from $-3.6 \mathrm{~kg}$ (95\% CI -4.6 to $-2.7 \mathrm{~kg}$ ) to $-3.5 \mathrm{~kg}$ $(95 \% \mathrm{CI}-4.4$ to $-2.6 \mathrm{~kg}$ ). This difference was approaching significance $(p=0.05)$ rather than previously being significant $(\mathrm{p}=0.03)$. An amended version of Table 3 appears here to highlight these changes.

\begin{abstract}
Author details
'School of Health and Population Sciences, University of Birmingham, Edgbaston, Birmingham B15 2TT, UK. ${ }^{2}$ School of Social and Community Medicine, University of Bristol, Canynge Hall, 39 Whatley Road, Bristol BS8 2PS, UK. ${ }^{3}$ Nuffield Department of Primary Care Health Sciences, University of Oxford, Radcliffe Observatory Quarter, Woodstock Road, Oxford OX2 6GG, UK. ${ }^{4}$ The Boden Institute of Obesity, Nutrition, Exercise and Eating Disorders, The University of Sydney, Level 2 Charles Perkin Centre D17, Sydney, NSW 2006, Australia.
\end{abstract}

Published online: 30 March 2016

References

1. Madigan CD, Daley A, Lewis A, Aveyard P, Jolly K. Is self-weighing an effective tool for weight loss: a systematic literature review and meta-analysis. Int J Behav Nutr Phys Act. 2015;12:104.

2. VanWormer JJ, Martinez AM, Benson GA, Crain AL, Martinson BC, Cosentino $\mathrm{DL}$, et al. Telephone counseling and home telemonitoring: the weigh by day trial. Am J Health Behav. 2009;33(4):445-54. doi:10.5993/ajhb.33.4.10.

\footnotetext{
* Correspondence: claire.madigan@sydney.edu.au

${ }^{1}$ School of Health and Population Sciences, University of Birmingham, Edgbaston, Birmingham B15 2TT, UK

${ }^{4}$ The Boden Institute of Obesity, Nutrition, Exercise and Eating Disorders, The University of Sydney, Level 2 Charles Perkin Centre D17, Sydney, NSW 2006, Australia
}

(c) 2016 Madigan et al. Open Access This article is distributed under the terms of the Creative Commons Attribution 4.0 International License (http://creativecommons.org/licenses/by/4.0/), which permits unrestricted use, distribution, and reproduction in any medium, provided you give appropriate credit to the original author(s) and the source, provide a link to the Creative Commons license, and indicate if changes were made. The Creative Commons Public Domain Dedication waiver (http://creativecommons.org/publicdomain/zero/1.0/) applies to the data made available in this article, unless otherwise stated. 


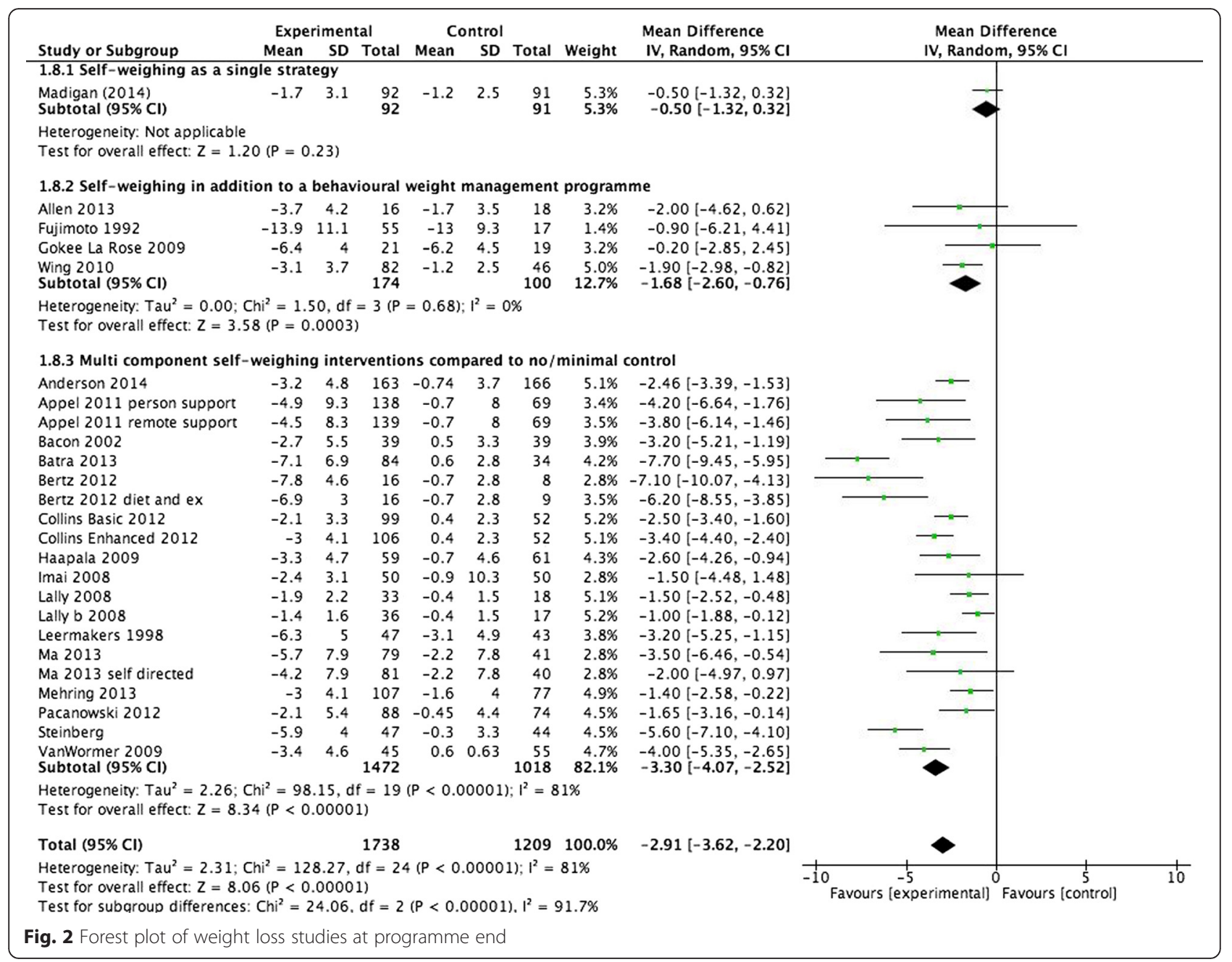

Table 3 Weight change outcomes

\begin{tabular}{|c|c|c|c|c|c|c|c|}
\hline & & $\begin{array}{l}\text { Trials } n \text { (number of } \\
\text { participants) }\end{array}$ & $\begin{array}{l}\text { Mean difference, } \\
\mathrm{kg}(95 \% \mathrm{Cl})\end{array}$ & $P^{2}$ & P & $\begin{array}{l}95 \% \text { prediction } \\
\text { intervals }\end{array}$ & $\begin{array}{l}\text { Sub group } \\
\text { analysis } P\end{array}$ \\
\hline & Weight Loss & & & & & & \\
\hline \multirow[t]{2}{*}{ Weight change } & Mean weight change at programme end & $20(2947)$ & $-2.91(-3.6$ to -2.2$)$ & $81 \%$ & $<0.01$ & & - \\
\hline & Mean weight change at follow-up & $3(185)$ & $-5.5(-11.4$ to 4.7$)$ & $86 \%$ & 0.04 & - & - \\
\hline \multirow{2}{*}{$\begin{array}{l}\text { Self-weighing/self- } \\
\text { regulation isolated. }\end{array}$} & Isolated strategy & $1(183)$ & $-0.5(-1.3$ to 0.3$)$ & - & - & - & - \\
\hline & $\begin{array}{l}\text { Behavioural weight management programme } \\
\text { plus self-weighing/self-regulation components } \\
\text { compared to the same behavioural programme }\end{array}$ & $4(274)$ & $-1.7(-2.6$ to -0.8$)$ & $0 \%$ & $<0.01$ & -7.5 to 4.1 & - \\
\hline \multirow{5}{*}{$\begin{array}{l}\text { Multi component } \\
\text { interventions }\end{array}$} & All & $15(2490)$ & $-3.3(-4.1$ to -2.8$)$ & $81 \%$ & $<0.01$ & -6.7 to 0.05 & - \\
\hline & Daily weighing & $7(795)$ & $-3.2(-4.8$ to -1.6$)$ & $90 \%$ & $<0.01$ & -9.5 to 3.1 & 0.95 \\
\hline & Less than daily weighing & $8(1695)$ & $-3.3(-4.0$ to -2.5$)$ & $65 \%$ & $<0.01$ & -4.6 to -1.0 & \\
\hline & Has accountability & $14(2177)^{+}$ & $-3.5(-4.4$ to -2.6$)$ & $82 \%$ & $<0.01$ & -8.9 to 1.9 & 0.05 \\
\hline & No accountability & $2(313)^{+}$ & $-2.3(-3.2$ to -1.5$)$ & $0 \%$ & $<0.01$ & - & \\
\hline
\end{tabular}

All studies are intention to treat using BOCF + One trial had three arms and subsequently an intervention arm in each subgroup 